\title{
The possibility of shrinkage strain reduction in cements mortars
}

\author{
Maciej Gruszczyński ${ }^{1, *}$, and Grzegorz Bajorek ${ }^{2}$ \\ ${ }^{1}$ Faculty of Civil Engineering, Cracow University of Technology, Cracow, Poland \\ ${ }^{2}$ Faculty of Civil and Environmental Engineering and Architecture, Rzeszow University of \\ Technology, Rzeszow, Poland
}

\begin{abstract}
The subject of the paper is presentation of action mechanism and effectiveness estimation of different types of chemical admixtures that make it possible to control the course of shrinkage strains associated with cement hydration process. There are presented tests results from the research program realization in which there were used the basic types of admixtures allowing for producing mortars and concretes with reduced or compensated shrinkage. In conducted tests there were applied admixtures based on calcium oxide, multi-molecule alcohol as well as water polymer dispersions (styrene-acrylic co-polymer - SA and styrene-butadiene latex SBR). Their influence onto the magnitude of shrinkage strain and strength development for cement mortars was analyzed.
\end{abstract}

\section{Mortars and concretes with reduced shrinkage}

Mortars and concretes, beside their undisputed advantages, have also some shortcomings such as:

- shrinkage,

- low tensile strength,

- insufficient adhesion of the fresh composite to the existing concrete base.

These failures are manifested especially in application of cement composites for executing such structures as:

- road pavements,

- industrial floors and floor bases,

- tanks,

- tunnels cases,

- repair systems for concrete and reinforced concrete structures.

Shrinkage of mortars and normal concretes is relatively well known and scientifically documented phenomenon. It is worth underlying that composite volume changes (shrinkage or swelling) result only from the matrix strains as the filler (aggregate) practically does not subject to strains/deformation.

Classical theory of concrete shrinkage [1] assumes that the reaction between cement and water results in the overall reduction of the mixture volume, i.e. in plastic shrinkage

\footnotetext{
${ }^{*}$ Corresponding author: mgruszczynski@pk.edu.pl
} 
(contraction). Plastic shrinkage, in opposition to the later drying shrinkage, is irreversible. Total shrinkage of concrete depends on numerous factors and the most important are:

- w/c ratio,

- amount and type of cement,

- amount and type of aggregate,

- application of chemical admixtures,

- heat and moisture condition of curing.

In order to minimize the unfavorable shrinkage strains for mortars and concretes there may be taken different material and technological interventions:

- selection of appropriate cement type (with lowest possible $\mathrm{C}_{3} \mathrm{~A}$ contents and surface area limited to $3200 \mathrm{~cm}^{2} / \mathrm{g}$ ) with the limitation of its amount in the mix,

- reduction of w/c ratio below the value of 0,50 (application of rheological admixtures),

- design of steel meshes reducing the shrinkage,

- application of fibre type additives (steel, synthetic or glass fibres),

- usage of anti-shrinkage and/or expansive admixtures,

- carrying out long-lasting and careful moisture curing of the element,

- appropriate design of elements and structures - proper amount and location of antishrinkage reinforcement, proper arrangement of dilatations.

Application of presented recommendations for minimization of shrinkage for cement composites is especially difficult for the case of constructing the road pavements and industrial floors. Among the investors there is observed a tendency for executing such structures with the highest load-bearing capacity within the system of no dilatations. This is due to the fact that dilatations constitute the weakest element in floor structure which is subjected to damages. Slab divided by dilatations is additionally exposed to characteristic deformations (boating) caused by the differences in shrinkage for lower and upper floor layers. Application of typical two layers of steel meshes relatively increases the construction cost and impedes the proper building-up of the concrete mix.

From this reason, from many years there have been carrying out the researches aiming to work out the effective chemical admixtures that could compensate for cement composite shrinkage strains as well as increase their bending strength - the crucial parameter for loadbearing capacity estimation and for designing the road pavements and industrial floors.

\section{Basic types of anti-shrinkage admixtures and additives}

Presently, in modern technology of concrete there exist three basic groups of admixtures and additives whose aim is to reduce shrinkage strains or even produce expansive composites. The following admixtures types may be included into shrinkage reducers:

- admixtures and additives based on calcium or magnesium oxides and sulfates,

- admixtures increasing the water boundness in the mix based on multi-molecule alcohol,

- polymer dispersion additives of different types.

\subsection{Expansive admixtures and additives based on calcium compounds}

Application of additive based on calcium sulfate (or calcium oxide $\mathrm{CaO}$ ) results in the expansion of binder in hydration process. It is due to the reaction of forming the ettringit (portlandit for the case of $\mathrm{CaO}$ ) from calcium oxide and water dispersions of calcium aluminates included in cement [2]. Ettringit crystals form the sheath on the grains of calcium sulfur-aluminate, resulting in significant grout volume increase (photo 1). 


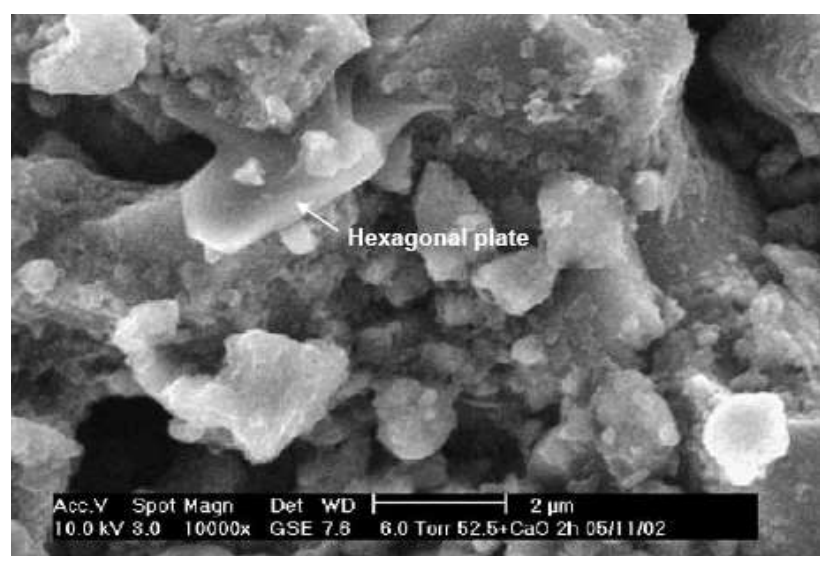

Photo 1. SEM picture of cement grout modified with $3 \%$ addition of expansive admixture based on $\mathrm{CaO}$ - visible the hexagonal portlandit crystals [3].

Imporatant issue in the process of ettringit formation is the shape and magnitude of crystals and time of their apperaence. It is vital that crystals causing the expansion form between $24^{\text {th }}$ and $72^{\text {nd }}$ hours of grain formation. If the reaction starts too early, i.e. when the grain is in plastic stage, volume changes will be overcame by this. And if the grain is too rigid than the expansion may cause its destrucion similarly to the case of sulfate corrosion [4].

Presented mechanism of action for expansive admixtures based on $\mathrm{CaO}$ and $\mathrm{CaSO}_{4}$ causes that the obtained structure of composites modified with such admixtures is more dense then for mortars or normal concretes. Crystals that are formed firstly fill the pores in cement paste, sealing its structures, and then cause the expansion.

\subsection{Anti-shrinkage admixtures based on multi-molecular alcohol}

Shrinkage reducers based on multi-molecular alcohol were worked out in Japan in the middle of the 80-ties and were introduced into practice at the beginning of the 90 -ties of the last century. Admixtures from this group are nonionic surfactants - they increase the water boundness in the mix and cause the shifting in time of the cement composite hardening process. As the surfactants, admixtures of such type reduce the surface tension of water, decreasing the pressure in capilary pores that according to Wittmann [5] can be expressed as:

$$
P=\frac{2 \gamma}{r}
$$

where : $P$-capilar pressure,

$\gamma$ - surface tension of liquid filling the pores,

$r$ - meniscus radius.

This effect causes the reduction of drying shrinkage due to decrease in distances between the planes in CSH structure [6,7]. Organic shrinkage reducers thanks to increase in mix cohesion and water boundness also influence the shape and magnitude of crystals being the products of cement hydration. Crystals of ettringit have a shape of prismatic needles and not typical hexagonal plates (photo 2). 


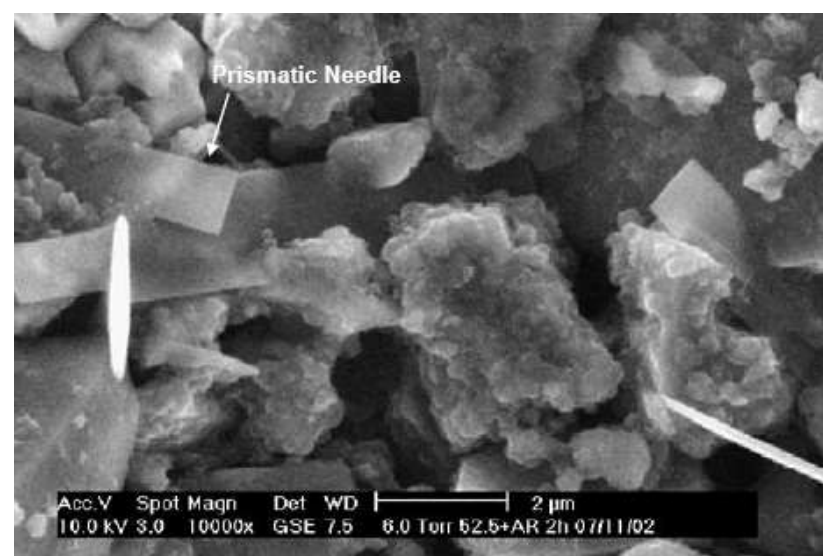

Photo 2. SEM picture of cement grout modified with $3 \%$ addition of organic shrinkage reducer SRA [3].

Unfavourable effect of application of admixtures from this group is possibility to decrease the composite strength within the range $5 \div 8 \%$ as a result of mix aeration $[3,6]$.

\subsection{Admixtures and additives of polymer dispersions}

Application of such admixtures and additives causes significant changes in cement composite structure. Polymer addition used with the amount exceeding $5 \%$ of cement mass results in formation of continuous membrane with high tensile strength that penetrates cement matrix and constitutes internal micro-reinforcement of the composite. Introduced polymer membranes have an ability to bridge the shrinkage micro-cracks. Polymer membranes surround not only the aggregate grains, but also cement grains by impeding the water access. That slows down the hydration process, but at the same time leads to obtaining the favorable fine-crystal structure of cement hydration products [8].

Addition of polymer dispersions causes meaningful reduction of transition zone thickness for cement grout and aggregate grains. Its porosity is significantly reduced as the free spaces are filled with targeted polymer particles which increases the contact surface between matrix and aggregate and finally results in density of inter-phase zone [9].

Around the aggregate grains as well as on the pores walls around the aggregate grains there is formed polymer layer which increases adhesion between different phases, mainly between hardened cement grout and aggregate, that significantly improves parameters of concrete and especially tensile and bending strengths [10].

Cement-polymer concretes and mortars are characterized with very beneficial usability properties:

- high bending strength $(2 \div 5$ times higher than for normal concrete),

- low value of shrinkage strains,

- high crack-resistance,

- very good adhesion to concrete base.

\section{Authors tests}

Realized research program aimed to estimation of the influence of expansive admixture (EXP) and organic shrinkage reducer (SRA) onto such properties of cement mortars as the course of shrinkage strains and strength development kinetics. 
In test program there were used expansive admixture EXP and admixture reducing shrinkage based on propylene glycol SRA.

Tests were carried out on mortars prepared on the base of CEM I 32,5R cement type and natural sand. Mass proportions for components were assumed as for standard mortar: cement:sand: water $=1: 3: 0,5$.

There were assumed the following dosage levels for shrinkage reducers:

- EXP: $1,2,3 \%$ of cement mass,

- SRA: $1,2 \%$ of cement mass.

The influence of applied admixtures reducing the cement composite shrinkage was confronted with the effect produced with the mortar modification by polymer dispersions based on styrene-acrylic co-polymer (SA) and styrene-butadiene latex (SBR) with the amount of $10 \%$ of cement mass.

Estimation of the magnitude of shrinkage strains was conducted with the application of shrinkage gutters with u-shaped cross-section and with dimensions $50 \times 100 \times 1000 \mathrm{~mm}$ (photo 3).
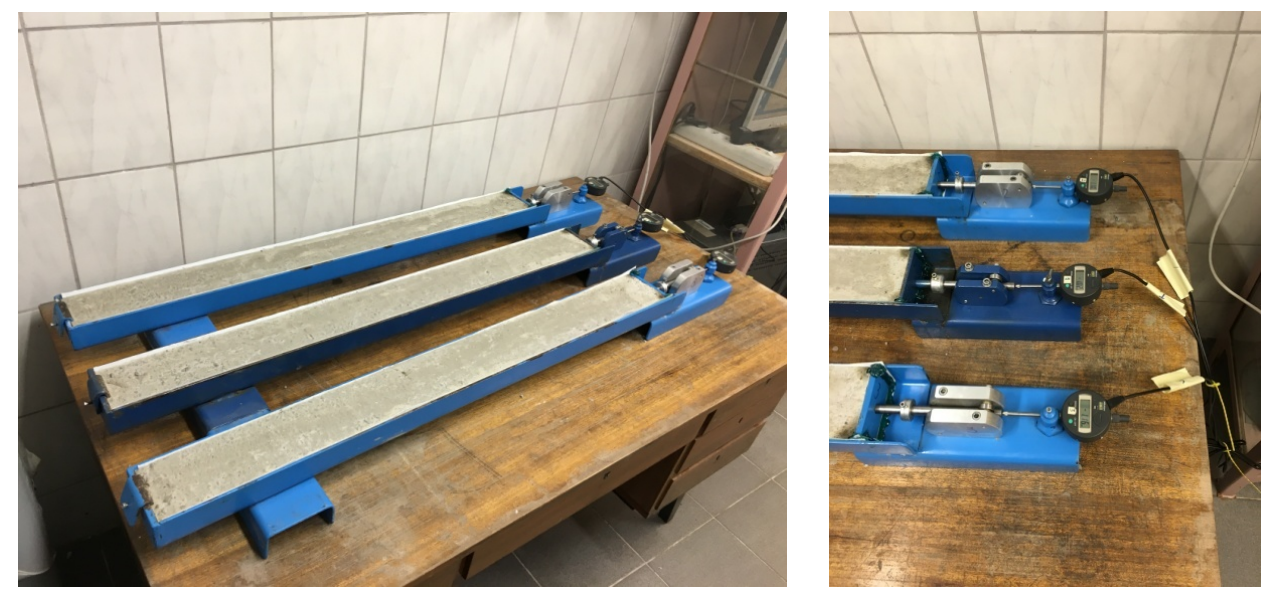

Photo 3. Shrinkage gutters with mounted displacement sensors registering the changes in length of samples.

Applied methodology of shrinkage strains measurements allows for automatic registration of results for assumed time intervals and the first measurements of the sample length is made immediately after its formation, which is impossible for application of measurements such as by DEMEC gauges or Amsler apparatus where the first measurements are made at least with few hours delay when shrinkage processes are highly advanced.

In conducted researches samples for shrinkage tests were stored in air conditions with temperature equal $20^{\circ} \mathrm{C}$ and moisture level $60 \%$. For the first 72 hours the samples surfaces were protected from water evaporation by the application of PE foil.

\section{Tests results}

The aim of conducted test program was to estimate the influence of specified admixture type onto shaping the course of shrinkage strains for cement mortars. In Fig.1 there is presented the course of shrinkage for mortars modified with shrinkage reducing admixture based on multi-molecule alcohol (SRA). 


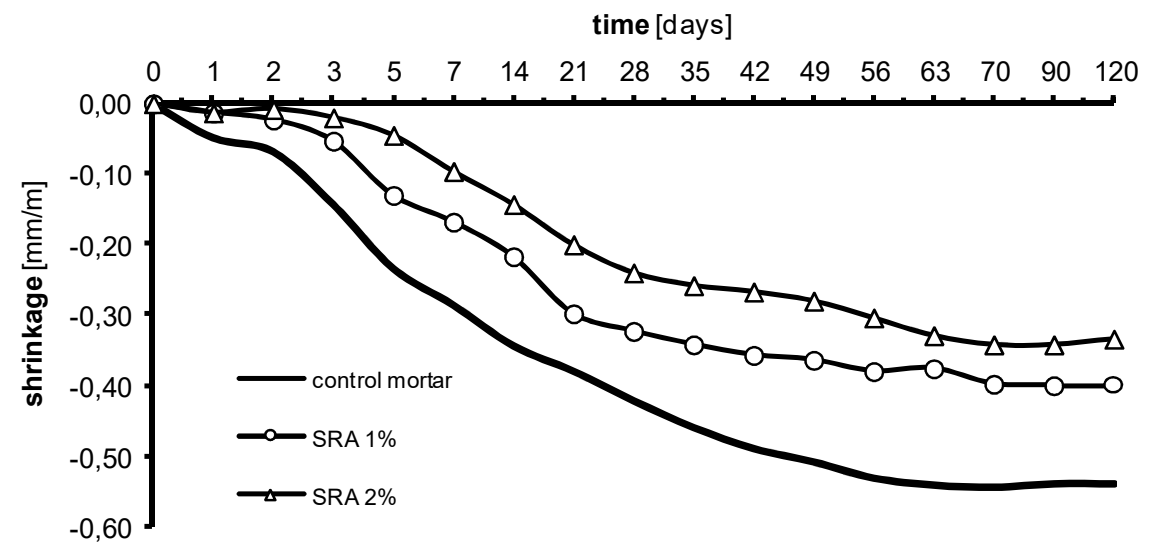

Fig. 1. Shrinkage for mortars modified with SRA admixture.

Analysis of results for shrinkage for mortars modified with SRA admixture indicates that it does not have an important influence on the course of shrinkage strains in comparison with standard mortar. Application of such admixture type causes the increase of water boundness in the mix, but also reduction in drying shrinkage component due to reduction in water surface tension. Its reduction is proportional to the amount of applied SRA admixture. Shifting the drying process in time makes it possible to conduct the proper curing of composite in order to assure the optimal heat and moisture conditions for the hydration process. Application of this admixture allows for reduction in the total shrinkage within the range $20 \div 35 \%$, depending on the dosage level.

In Fig. 2 there is presented the course of shrinkage strains for mortars modified with addition of $1 \div 3 \%$ of cement mass of EXP expansive addition based on $\mathrm{CaO}$.

Analysis of results indicates that application of expansive addition EXP results in expansive reaction lasting between 24 and $48 \div 60$ hours after mortar preparation. The magnitude of increasing is proportional to the addition dosage level.

It is worth noticing that application of EXP expansive additive does not influence significantly the drying shrinkage of composite which remains constant for mortars with EXP addition with the dosage $1 \div 3 \%$ of cement mass. Drying shrinkage is practically constant for those mixes and is close to the value of $0,30 \mathrm{~mm} / \mathrm{m}$. For such type of modification obtaining the material with compensated shrinkage or even expansive composite requires such dosage of admixture that causes reaction rise compensating the drying shrinkage. Application of such type of admixture with the amount of $1 \div 3 \%$ of cement mass made it possible to reduce the final shrinkage within the range of $30 \div 60 \%$ in comparison with standard mortar. 


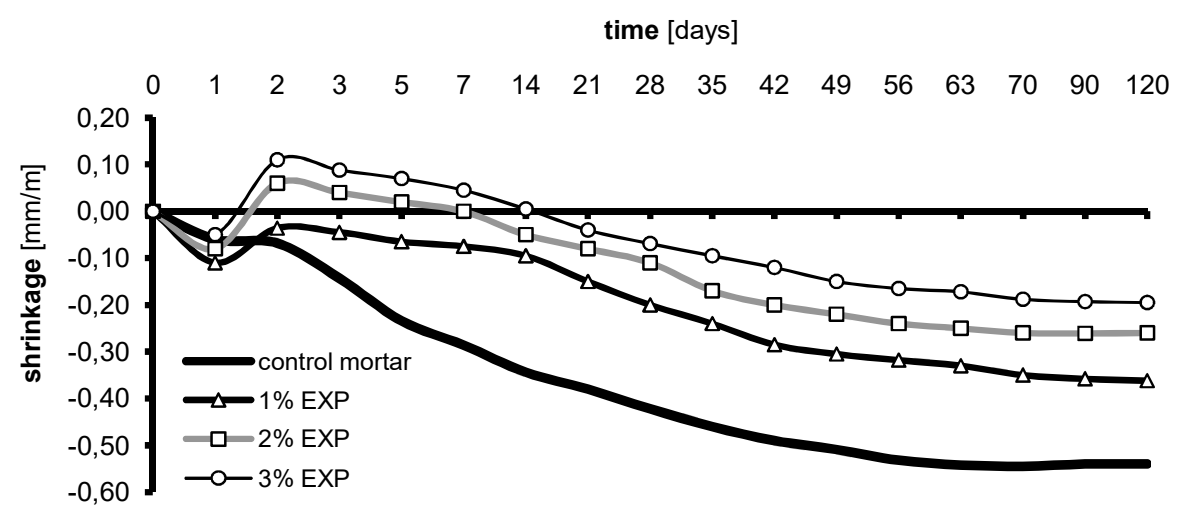

Fig. 2. Shrinkage for mortars modified with admixture EXP.

In conducted reserach program there was prepared also mortar modified simultaneously with two types of admixtures: organic shrinkage reducer SRA and EXP expansive addition. Dosage level for both preparations was equal to $2 \%$ of cement mass. The course of shrinkage strains for such type of mortar is given in Fig.3.

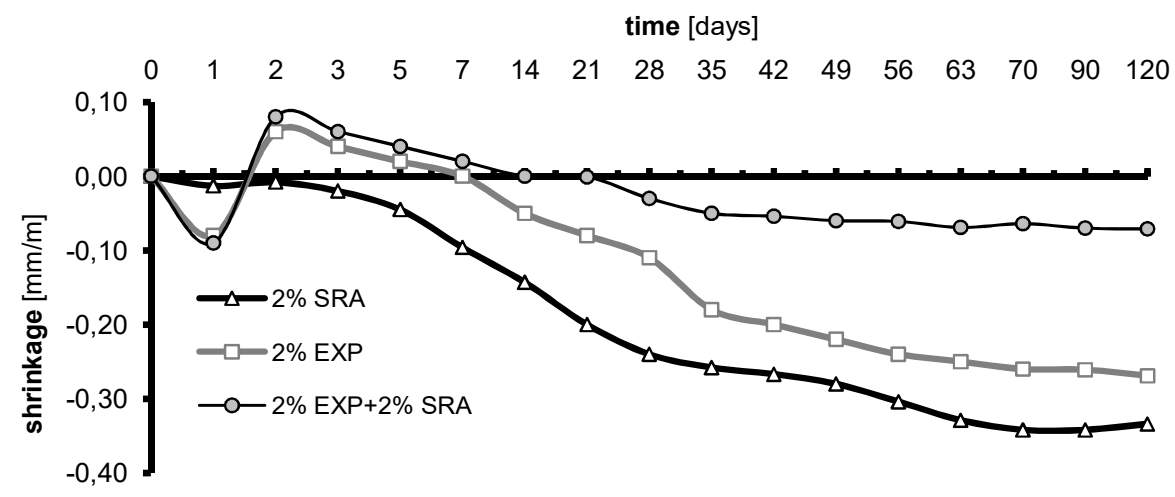

Fig. 3. The course of shrinkage for mortars modified with SRA admixture ( $2 \%$ of cement mass) and with EXP expansive addition ( $2 \%$ of cement mass).

Results from tests indicate that simultaneous application of both preparations made it possible to reduce drying shrinkage by about $50 \%$. As a result, there was obtained the composite that is characterized by the similar expansion as the mortar with EXP 2\% addition that lasts between 24 and 48 hours after mortar preparation. The effect of simultaneous application of both types of admixtures is reduction of drying shrinkage from 0,32 to $0,18 \mathrm{~mm} / \mathrm{m}$. Shrinkage of obtained mortar was stabilized after about 28 days of curing at the level of $0,08 \mathrm{~mm} / \mathrm{m}$, which allows for classification of this mortar to the category of low-shrinkage materials.

As indicated by researches carried out by C. Maltese [3] the favorable reduction in shrinkage is due to synergic inter-reaction between admixtures of SRA and EXP types. On the base of conducted SEM analysis (photo 4) there was confirmed the hypothesis that compensation of shrinkage strains is possible by massive forming of longitudinal portlandit crystals which produce the accretion effect $[3,6,10]$. 


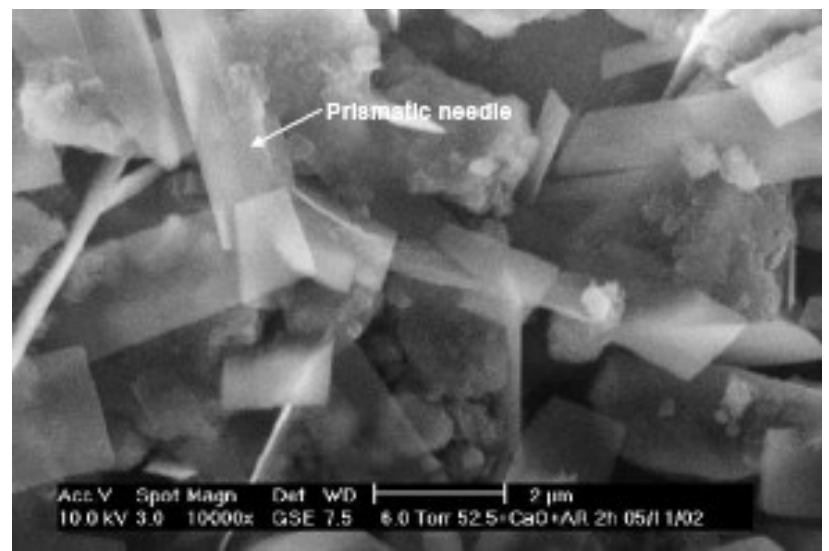

Photo 4. SEM photo of grout modified with 2\% SRA and 2\% EXP addition [3].

Chatterji [10] states that simultaneous application of SRA and EXP addition types of composite modification results in forming of favorable types of portlandit crystals due to reduction in solubility of calcium hydroxide. Application of SRA type admixture (built with hydrophobic organic particles) together with EXP expansive addition results in reduction in solubility of salt in the solution, contributing to forming big crystal forms and supporting the expansion compensating the shrinkage strains.

In Fig. 4 there is presented the course of shrinkage strains for mortars modified with addition of polymer dispersions based on styrene-butadiene latex (SBR) and styrene-acrylic co-polymer (SA) applied with the amount of $10 \%$ of cement mass.

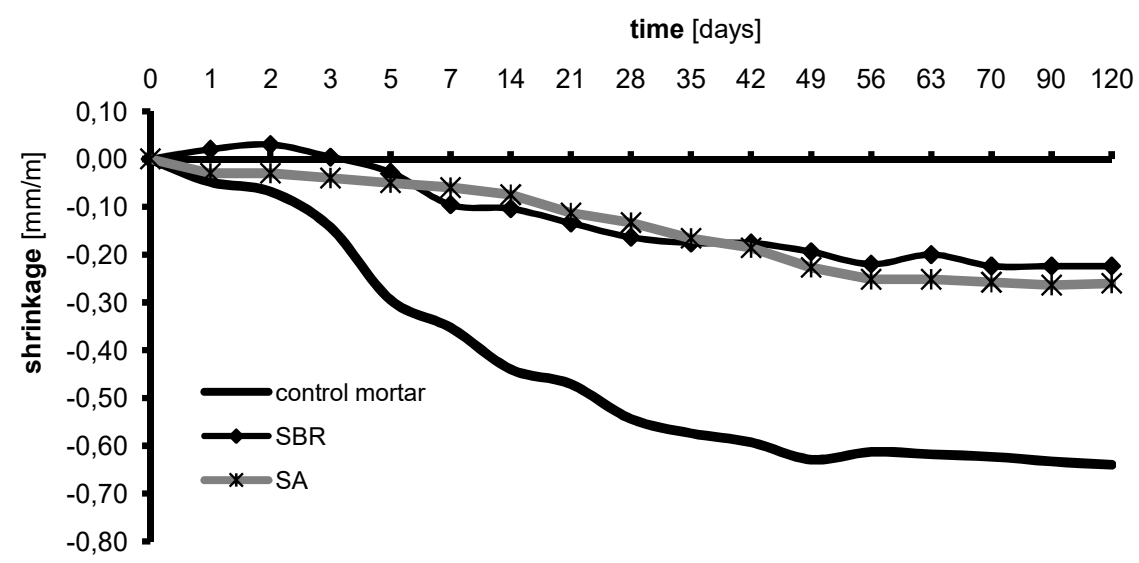

Fig. 4. The course of shrinkage for mortars modified with $10 \%$ addition of styrene-butadiene latex (SBR) and styrene-acrylic co-polymer (SA).

Analysis of results indicates that both additions application results in the change of character of the course of shrinkage strains in comparison with the standard mortar. For both cement-polymer composites there is observed significant reduction in the final shrinkage within the range of $60 \%$ in comparison with standard mortar. This is produced by inter-penetration of cement matrix by polymer membrane that surrounds the aggregate and cement grains forming the spatial structure of "honeycomb" type. Additional favorable effect of polymer action is fact that polymer membranes surround the cement grains restricting the access of water and by this slow down the hydration process. The products that are formed, especially portlandit crystals, are characterized with favorably altered 
structure $[8,9]$. The other advantageous effect is the ability of polymer particles to bridge the shrinkage micro-cracks that appear in cement grout.

Conducted tests program showed that anti-shrinkage addition of different types influence the strengths of tested mortars in a different manner. The strength of mortars modified with SRA shrinkage reducer based on propylene glycol is about $5 \div 8 \%$ lower in comparison with the standard mortar within the whole maturity period (Fig. 5). Reduction in composite strength is proportional to the amount of SRA admixture application and is the result of admixture aeration property.

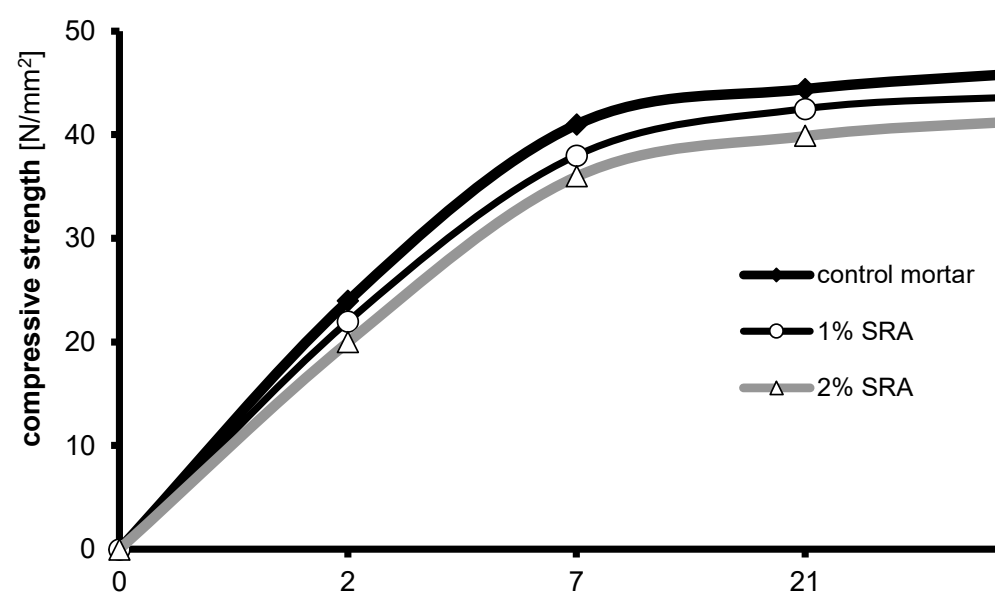

Fig. 5. Kinetics of development of strength for mortars modified with SRA organic shrinkage reducer.

In Fig. 6 there are given the curves for kinetics of development of strength for mortar modified with EXP expansive admixture based on $\mathrm{CaO}$ and mortar simultaneously modified with $2 \%$ addition of EXP admixture and $2 \%$ of SRA shrinkage reducer.

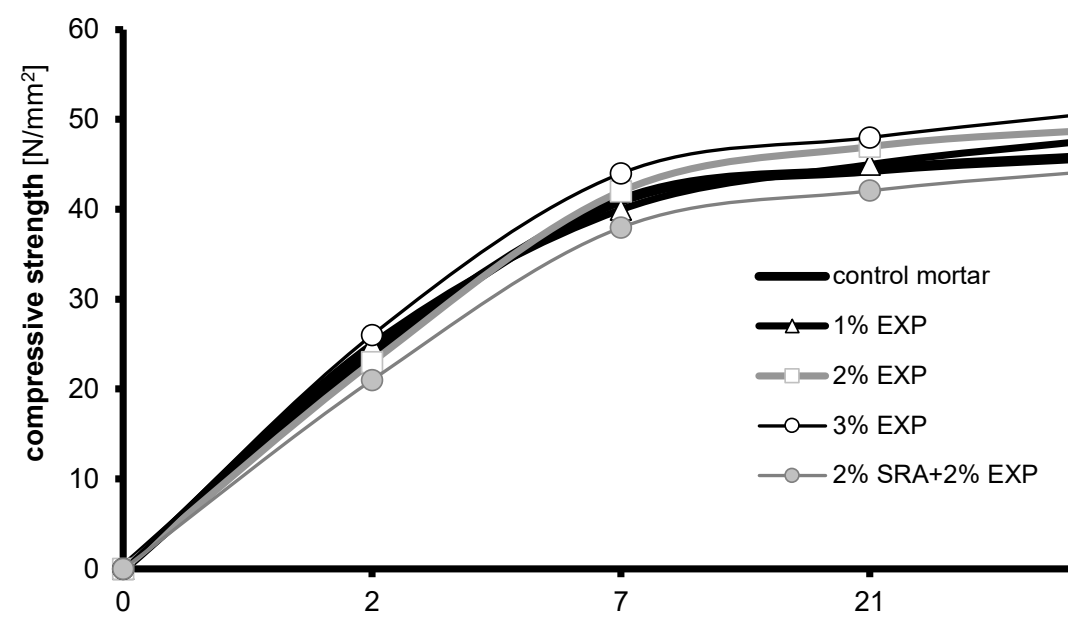

Fig.6. Kinetics of development of strength for mortars modified by EXP expansive additive based on $\mathrm{CaO}$ and by simultaneous application of EXP and SRA shrinkage reducer.

Application of EXP expansive admixture based on $\mathrm{CaO}$ with the amount of $1 \div 3 \%$ of cement mass for modification of mortar results in slight increase of composite strength. It 
constitutes a compensating factor for the loss of strength caused by mortar aeration for simultaneous modification with EXP and SRA admixtures applied with the amount of $2 \%$ of cement mass.

For the case of mortars modified with polymer additions based on styrene-acrylic copolymer SA and styrene-butadiene latex SBR applied with the amount of $10 \%$ of cement mass, no significant changes in compressive strength were noticed. Thanks to favorable changes in composite structure, which is inter-penetrated by polymer membranes with high tensile strength, there is observed very meaningful increase (more than 100\%) in bending strength, both for 7 and 28 days of maturity, in comparison with the standard mortar (Fig.7). This favorable change, coupled with shrinkage reduction, prejudges about the application of polymer modified cement composites for constructing the floors and floor bases that may be realized in system without dilatations [11]. For mortars modified with SRA organic shrinkage reducer and EXP expansive additive, such significant changes with bending strength in comparison with the standard mortar are not observed.

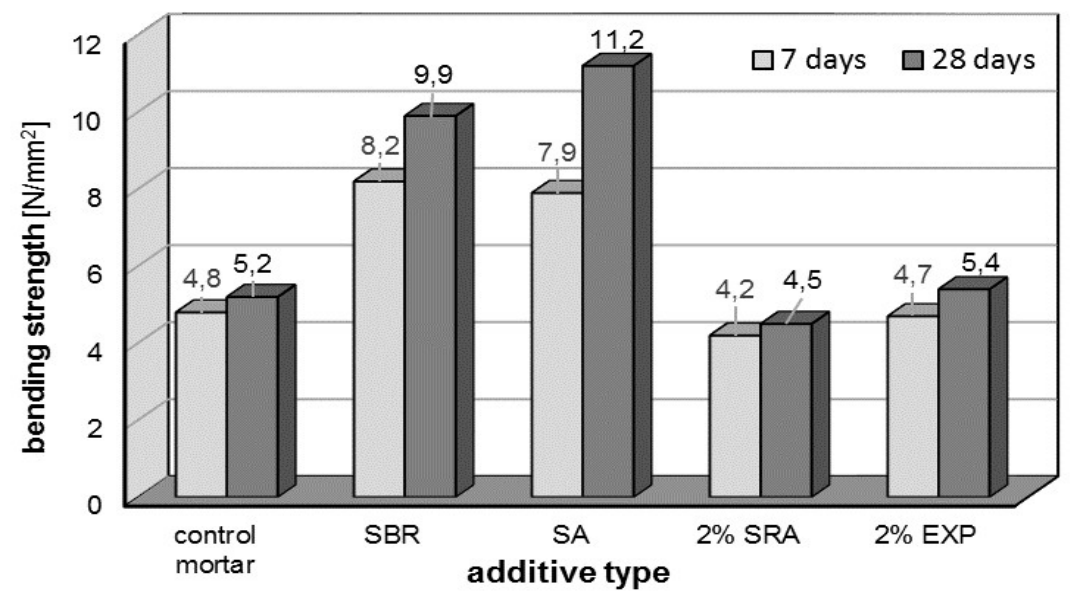

Fig. 7. The influence of SBR and SA polymer additives as well as SRA and EXP admixtures onto mortar bending strength after 7 and 28 days of maturity.

\section{Conclusions}

Conducted tests together with analysis of obtained results constitute the basis for formulating the following general conclusions:

- Application of shrinkage reducer on the base of propylene glycol SRA for modification of mortars makes it possible to reduce the shrinkage strains of cement mortar within the range of $25 \div 35 \%$ in comparison with the standard mortar.

- Expansive addition EXP based on $\mathrm{CaO}$, thanks to accretion reaction between 24 and 72 hours after composite preparation allows for the reduction in shrinkage strains within the range of $30 \div 60 \%$ in comparison with standard mortar.

- Completed research program indicated the favorable synergic effect of co-operation between SRA and EXP types of admixtures that results in obtaining the mortars with compensated shrinkage.

- Application of polymer dispersion additive, both of SBR and SA type, with the amount of $10 \%$ of cement mass results in the reduction of both early and long-term shrinkage strains within the range of $60 \%$ in comparison with standard mortar. 
- Polymer additives, due to favorable changes within the grout structure and especially within the contact zone grain-grout, as well as thanks to the presence of high strength polymer membranes, make it possible to increase significantly the composite tensile strength at bending.

- For SRA shrinkage reducer and EXP expansive admixture there was not noticed their significant influence onto compressive or bending strength of mortars.

\section{References}

1. Kurdowski W.: Chemia cementu. PWN, Warszawa (1991)

2. Konik Z., Małolepszy J., Roszczynialski W., Stok A.: Wpływ dodatku ekspansywnego na właściwości fizyczne wybranych cementów. Cement Wapno Beton 4 (2006)

3. Maltese C., Pistolesi C., Lolli A., Bravo A., Crulli T., Salvioni D.: Combined effect of expansive and shrinkage reducing admixtures to obtain stable and durable mortars. Cement and Concrete Research 35 (2005)

4. Roszczynialski W., Konik Z., Małolepszy J., Stok A.: Wykorzystanie gipsów $z$ odsiarczania spalin do otrzymywania siarczanowo-wapniowego spieku, stanowiącego główny składnik dodatku ekspansywnego. Cement Wapno Beton 1 (2006)

5. Wittmann F.: On the action of capillary pressure in fresh concrete. Cement and Concrete Research 6 (1976)

6. Suzuki M., Tanimura M., Sato R.: The effect of autogenous shrinkage on flexural cracking behavior of reinforced HSC beams and improvement by using low-shrinkage $H S C$. Fourth International Seminar on Self-desiccation and Its Importance in Concrete Technology, 20 June 2005, Gaithersburg

7. Czarnecki L.: Betony polimerowe. XVII Ogólnopolska Konferencja Warsztat Pracy Projektanta Konstrukcji, Ustroń (2002)

8. Gruszczyński M.: Wpływ rodzaju i ilości dodatku polimerowego na wielkość skurczu zapraw i betonów cementowych. Cement Wapno Beton 3 (2007)

9. Czarnecki L., Łukowski P.: Wpływ domieszek i dodatków polimerowych na trwałość betonu. Cement Wapno Beton 6 (2003)

10. Chatterji S.: Mechanism of expansion of concrete due the presence of dead burnt CaO and $\mathrm{MgO}$. Cement and Concrete Research 25 (1995)

11. Tazawa E., Miyazawa S., Influence of binder and mix proportion on autogenous shrinkage of cementitious materials, Journal of Materials, Concrete Structures and Pavements of JSCE No.502, V-25 (1994) 